\title{
Mining and the Sustainable Development Goals: A Systematic Literature Review
}

\author{
Rafael Fernandes de Mesquita ${ }^{1,2,3 *}$, Andre Xavier ${ }^{1}$, Bern Klein ${ }^{1}$ and Fatima Regina Ney Matos ${ }^{2}$ \\ ${ }^{1}$ Norman B. Keevil Institute of Mining Engineering, University of British Columbia, Vancouver, Canada \\ ${ }^{2}$ Graduate Program on Business Administration, Universidade Potiguar - UnP, Natal-RN, Brazil \\ ${ }^{3}$ Instituto Federal de Educacao, Ciencia e Tecnologia do Piaui - IFPI, Piripiri-PI, Brazil
}

\begin{abstract}
United Nations members are signatories of the 17 Sustainable Development Goals (SDGs). Even though it does not make it legally binding to the country members, the SDGs establishment incites national and managerial frameworks to achieve the SDGs. The mining industry inserts itself in this context by its global presence and frequent location within ecologically sensitive and less developed areas. This paper aims to consolidate the state of academic research on mining, sustainability and sustainable development, by organizing the results of previous studies within a systematic review on the SDGs set. To do so, the ISI Web of Science ${ }^{\mathrm{TM}}$ Core Collection database was chosen as a database of record, as it is one of the most widespread databases of academic journals. We have used all years available in the ISI database, from 1945 to 2016 (for complete years). The systematic review process comprised of five steps: (i) to search terms [("sustainability" or "sustainable development") and mining] on the database and to apply filters of criteria; (ii) organizing papers; (iii) metrics and relations between papers and authors; (iv) classification of the results through content analysis techniques; and (v) synthesis. The results were divided in two groups: the highly cited and the most recent papers, to include papers that have academic impact and those which show the newest contributions to the field. The results showed that, in spite of a growing amount of publications in the past years that relates to mining and sustainability, the main focus of these publications are still on the environmental dimensions of the UN goals. This suggests that more practical and academic work in the mining sector are required to fill in the blank spaces regarding the other set of goals that compose the SDGs framework.
\end{abstract}

Keywords: mining, sustainability, sustainable development, sustainable development goals, bibliometrics

\section{Introduction}

A total of 193 United Nations members are signatories of the 17 Sustainable Development Goals (SDGs). Even though it does not make it legally binding to the country members, the SDGs establishment incites national and managerial frameworks to achieve the SDGs. The mining industry inserts itself in this context by its global presence and frequent location within ecologically sensitive and less developed areas (Atlas 2016). The goals are important because they add common targets for different countries and easily establish discernible criteria for it (Costanza et al 2016).

A forward-looking approach like the SDGs would be able to attach the sustainable development framework with profitable activities taken by the mining companies (Starke 2016). This paper aims to consolidate the state of academic research on mining, sustainability and sustainable development, by organizing the results of high impact previous studies and recent publications, within a systematic review, on the SDGs set. By doing so, the results can portray the actual concern and the lacks that the academic field had on this subject in comparison to the UN contemporary agenda.

\section{Method}

The systematic review process comprised of five steps: (i) to search terms [("sustainability" or "sustainable development") and mining] on the database and to apply filters of criteria; (ii) organizing papers; (iii) metrics and relations between papers and authors; (iv) classification of the results through content analysis techniques; and (v) synthesis and conclusion. The results were divided in two groups: the highly cited and the most recent papers, to include papers that have academic impact and those which show the newest contributions to the field.

For the first three steps of the study, a bibliometric research was conducted, which is a quantitative and statistical technique for measuring production and dissemination of scientific knowledge indexes (Diodato and Gellatly 2013), based on ISI Web of Knowledge/Web of Science $^{\mathrm{TM}}$ (Web of Science Core Collection: Citation Indexes without the conference proceedings indexes). The data were collected throughout the search period available in the database for full years (1945-2016). The collection was carried out from the search of the terms in "topic": title of articles, abstracts, author's keywords and created keywords (keywords plus).

* Corresponding Author: R.F. Mesquita, rafael.fernandes@ifpi.edu.br, phone: +55 86-99839-0521

Copyright @ 2017 Canamaple Academia Services, http://press.camdemia.ca

DOI: 10.15273/gree.2017.02.006 
After the search, a refinement of the found papers was carried out, excluding proceeding papers, reviews, editorial material, letters, news items, meeting abstracts and book chapters. Only articles were kept for the analysis. This way 1157 papers were identified and used as a set of articles for the bibliometric analyzes proposed in this research. After the data collection, the material was analyzed by exporting these data to the HistCite ${ }^{\mathrm{TM}}$ bibliometric analysis software package, in order to organize information and facilitate interpretations. The most cited articles in the Web of Science (global scores) and those most cited in the set of selected articles (local scores) were related to each other in a historiogram. In addition to this analysis provided by the software, the texts of the ten articles that composed each one of the scores and the ten most recent papers were analyzed using content analysis techniques for systematic reviews (Finfgeld-Connett 2014) to synthesize and organize their approaches and results within the Sustainable Development Goals (SDGs). The results of these analyzes are presented in the following section.

\section{Results}

In this section, the results are shown in two parts, the first one is the bibliometric results and the second one is the content analysis outcomes.

After conducting the bibliometric research in the core collection of the Web of Science ${ }^{\mathrm{TM}}, 1157$ articles on Mining and Sustainability/Sustainable Development were identified. These articles are published in 491 different journals indexed to the database in question and written by 3230 authors who have links to 1334 institutions located in 93 countries. For the accomplishment of these articles 44,431 references were used, with an average of approximately 38 references per article. Figure 1 shows the yearly output records of published papers which presents a crescent line with the higher score at 2016 (194 papers).

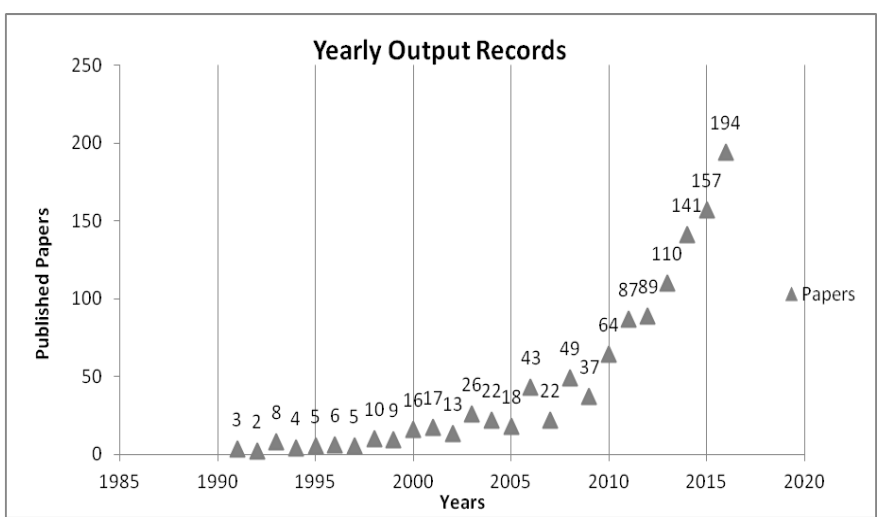

Figure 1. Yearly output records of published papers 1991-2016.

Figure 2 shows the top 10 authors in number of published papers with their score of citations in the whole Web of Science ${ }^{\mathrm{TM}}$ database and the top 10 countries with their main university in relation to studies production on the subject of mining and sustainability/sustainable development.

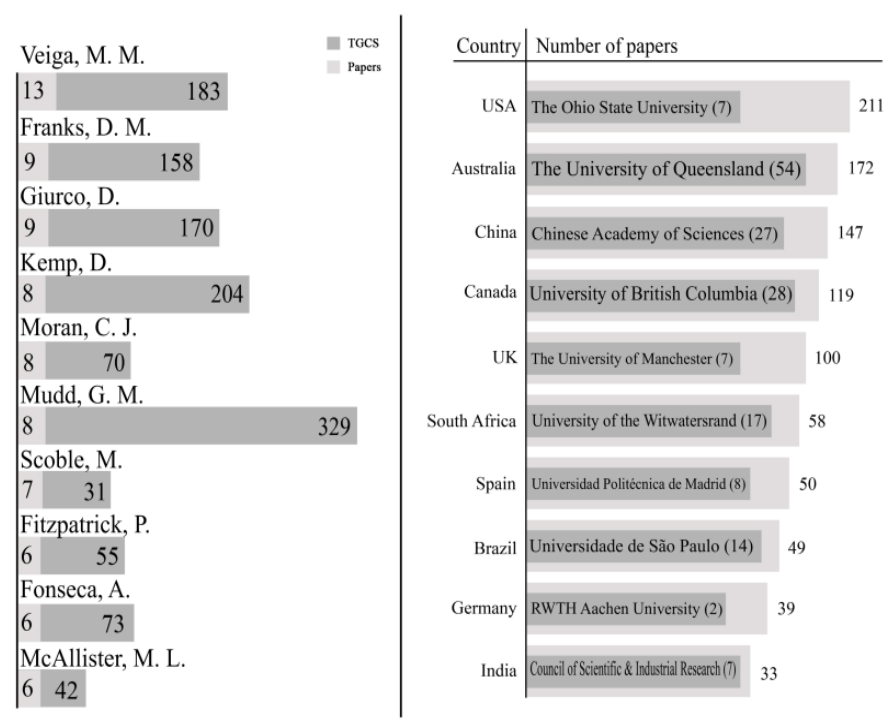

Figure 2. Top 10 authors in number of papers with their Total of Global Citation Scores (TGCS) and top 10 countries in number of papers with their most productive university in relation to the subject of mining and sustainable development/sustainability.

Marcelo Veiga is the top author for this subject with 13 papers. He teaches at the University of British Columbia UBC located in Canada, which is the fourth country in the ranking of published papers on this theme. The most cited author is Gavin Mudd who teaches at Monash University, Australia. Figure 2 also shows the countries and the main university for each one of them in number of papers.

Figure 3 is a graph that shows the relations between the two most cited groups of papers. The GCS group presents a singular citation relation: the text of Jenkins and Yakovleva (2006) cites the work of Hilson and Murck (2000) when argues that the sustainable development in the corporate mining context requires continuous commitment to environmental issues, from mineral exploration, through operation, to closure. The other texts in this group are not related to each other. The LCS group indicates more relationships between the works, repeating the presence of Hilson and Murck (2000) as an article of authority, which other studies use as a theoretical basis in their research. In this graphical relation, Whitmore (2006) can also be indicated as an authority, since there are others that are based on his contributions and they receive quotations later. Jenkins and Yakovleva (2006) and Mudd (2007) are hub or connection articles, updating latter contributions and connecting it to more recent studies.

The content analysis results are divided according to the seventeen sustainable development goals (SDGs), indicating the articles that present approaches, results or analysis topics associated with each goal. For this analysis the two most cited groups of articles presented in Figure 4 and the ten most recent articles of the bibliometric research database were analysed. The texts have been read in full and categorized as follows. 


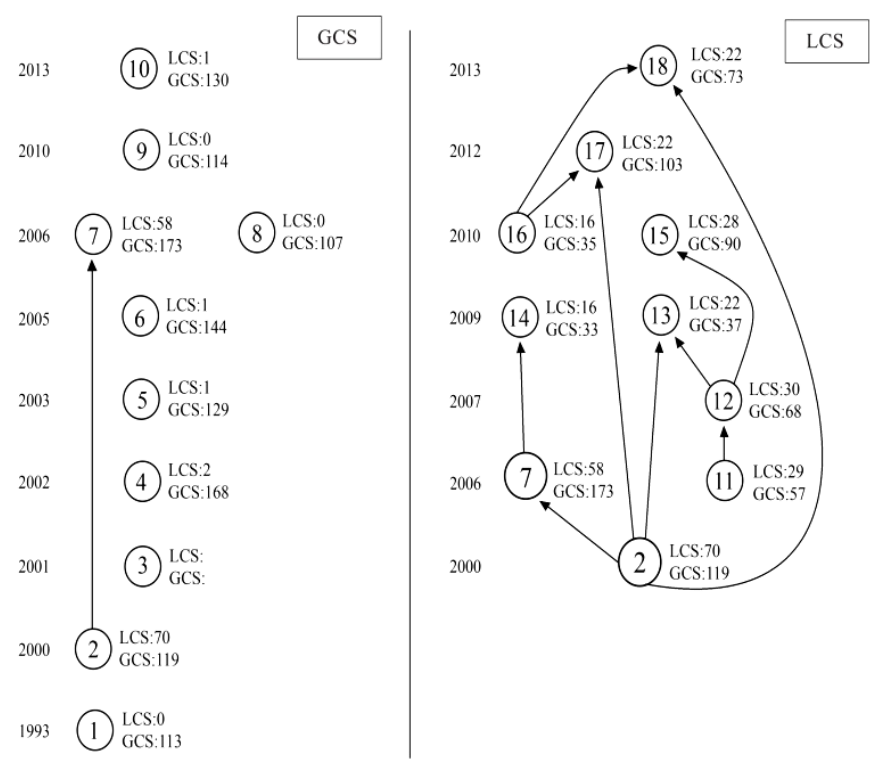

Figure 3. Global Citation Scores (GCS), Local Citation Scores (LCS) and relations between the ten most cited articles for each score.

Graphic subtitle: 1-West (1993); 2-Hilson and Murck (2000); 3Utzinger et al (2001); 4-Custodio (2002); 5-Mench et al (2003); 6Alcott (2005); 7-Jenkins and Yakovleva (2006); 8-Müller et al (2006); 9-Walker et al (2010); 10-Sayer et al (2013); 11-Whitmore (2006); 12-Mudd (2007); 13-Worrall et al (2009); 14-Perez and Sanchez (2009); 15-Mudd (2010); 16-Kemp (2010); 17-Prno and Slocombe (2012); 18-Owen and Kemp (2013).

Before addressing the content analysis to each SDG, it is imperative to indicate what Hilson and Murck (2000) clarify as sustainable development practices to the mining industry perspective. The authors' point of view embraces almost all the SDGs and points out processes that mining companies should adopt to become more sustainable. Those are: cleaner technologies, corporate responsibility extended to stakeholder groups, sustainability partnerships, improved planning and training, implementation of environmental management tools, all associated with a proactive attitude towards a profitable sustainable development from exploration to post-closure. The work still lacks the issues of hunger, gender equality, affordable and clean energy, reduced inequalities, climate actions and life on land, but seems to be the basilar guide for all the others researches that came after. The problem that is explained by Hilson and Murck (2000) is the failure on elucidating how to apply the sustainable development in the mining context, more specifically to provide suitable and clear guidelines for this application. The SDGs' linked to mining (Atlas 2016) can provide targets that seem to help addressing this issue.

Mining, good health and well-being (SDG3) Utzinger et al (2001) portray a twenty-year period of malaria control at a copper mine in sub-Saharan Africa. The interest is awakened by the reappearance of the disease in international health agendas in the early 2000s. The disease control or its eradication is not just an altruistic aim, but a way to attract and maintain the labour force for the exploitation of natural resources. Malenović Nikolić et al (2016) develop a project management process to improve the environmental protection/management system of mining and energy complex justifying their interest with the fact that those organizations are the dominant source of air pollutions in Serbia.

Mining, clean water and sanitation (SDG6) Custodio (2002) points out the problem of groundwater exploitation, the uncertainty of how to measure the damage with overexploitation and the different perception of groundwater uses. When the regional context is at stake, groundwater mining may be economically admissible, justified and not necessarily bad from the ethical point of view. There are some countries that depend almost exclusively on groundwater resources (i.e. Denmark) and this consumption is ethically admissible even knowing that the source is not a renewable one and the large exploitation leads to a water-quality deterioration. A broad perspective of groundwater use, pointed out by Custodio (2002), showed that scientific, technical and social progress may be able to help in solving the matter of groundwater uses towards a sustainable way of exploring this source of water.

The water security of cities located in arid lands becomes a problem with the increased level of water demand for drinking, agricultural and mining activities and decreases of groundwater and precipitations (Salinas et al 2016). The potential water scarcity problem plays a role in the mining sustainability programs.

Mining and affordable, clean energy (SDG7) Despite of being the only paper that is not directly related to the mining industry, Walker et al (2010) describe the synthesis, characterization and performance of the device of an organic salt which can be a substitute for batteries produced by finite mined materials. The sustainability matter is the driver for this research on alternative energy.

Mining, decent work and economic growth (SDG8) The Jevons' Paradox, recalled by Alcott (2005), discusses the technological change with efficiency gains associated with increases in production and consumption. The trade-off is presented in the coal supply duration scenario, but it is a broader question and the consumer behavior is a balance factor for a sustainable economic growth. Assuming that the labor force is increased when technological efficiency cheapened the products, as and because of the higher demand for them, the consumption and productions patterns must be adapted to use less natural non-renewable resources, so the paradox could be up to a solution. Whitmore (2006) addresses the problem of the supposed increased need for more mines and other issues, like the claim that mining catalyses development, the belief that technical fixes can solve almost all the problems and the conviction that those opposed to mining are ignorant, like NGOs and antidevelopment groups that expose the "fallacy of sustainable mining". The author argues that sustainability implies in something different that depends on the point of view of mining companies, small scale miners, artisanal miners or those who are affected by mining exploration. The emperor's new clothes, like Whitmore (2006) describes the sustainable mining, are barely there and his dubiety is 
related to greenwashing actions, mistrusted dialogues and disclosure of information. Papong et al (2016) discuss the social sustainability considering the workers' issues in a way to assess social impacts, pointing out the mining industry in China as the one with the highest level of fatal and non-fatal occupational injuries.

Mining and sustainable cities, communities (SDG11) - Mining iron urban waste improves the sustainable chain of iron production (Müller et al 2006). Custodio (2002) contributes to this topic when brings up the matter of groundwater exploitation, exhibiting a positive side for increasing the cost for its use when there is no other cheap service available, which leads to the possibility of water saving without decreases of quality of life by the development of more sustainable exploitation ways.

The life cycle of mines includes a post closure phase and Krzemień et al (2016) present a framework with management practices to achieve sustainability in underground coal mines.

Mining and responsible consumption, production (SDG12) - Müller et al (2006) highlight the production and consumption of iron, the most widely used metal in the world, which has slowly transformed from primary (ore) to secondary (scrap) production. The authors argue that if all obsolete iron were to be reused and recycled, primary iron production would be waived, which could also be supported by the reduction of the use of iron in the production of goods. Sayer et al (2013) advocate for a best agricultural production and the conservation of environmental values by using ten principles for the landscape approach. Those principles were focused on the agricultural production, but also extend the relation with all the other uses of lands that compete with environmental and biodiversity goals, like mining.

The resource intensity of gold mining, which includes water, energy, chemical consumption and greenhouse emission related to the ore grade throughput is beginning to increase substantively, especially in relation to the decline in ore grades. The sustainability of gold mining pointed out by Mudd (2007) and his broader discussion (Mudd 2010), embracing the triple bottom line (social, economic and environmental aspects), give us a consideration about an industry that profits over exploration of finite resources with well known environmental impacts and its sustainable future, which depends on more complex debates involving economics, scientific advances, social and environmental concerns rather than just an ecological matter. Calvo et al (2016) examine the copper mining industry quantifying the increases of production and energy consumption, a relation that shows fewer results with more depletion of resources.

Mining and life on land (SDG15) - This is the goal that most closely approximates the results and reflections of West's (1993) work. The oldest paper among the most cited group approaches biodiversity, its importance and value in relation to human concerns: morality, aesthetics, economics and advantages that natural ecosystems can provide. Mining enters this discussion when the author argues about the difficulty of satisfactorily re-establishing the vegetation of a surface for its use for mining. The paper focuses on the preservation of fauna and flora, but the study is limited to ecology and the responsible use of natural resources, which the author defends as a preservation of processes, not of organisms, that allows a continuous balance of life on the planet. Mench et al (2003) discuss the inactivation of trace elements on the fine-grained spoil of the former gold mine of Jales (Portugal). After sixty years of operation, the Jales mine is characterized by an excess of mineral elements, low water and nutrients content. The authors argue that it is uncertain whether the soil once contaminated can establish a sustainable vegetation cover.

Mining, peace, justice and strong institutions (SDG16) - Kemp (2010) explains the community relations in the mining industry by a conceptual level discussion that argues for a de-attachment from the public relation perspective, which is concerned by the company reputation, to one that professionalizes those relations for the empowerment and betterment of local people. Prno and Slocombe (2012) and Owen and Kemp (2013) examine the social license to operate (SLO), its emergence from a context that communities urge for more involvement in the decision-making process, but the results of SLO uses leads to a gap between external expectations and industry's outcomes, becoming just a way to avoid overt oppositions rather than a process that could engage stakeholders and companies. Essah and Andrews (2016) also indicate a discrepancy between the experienced perception from the local people and the practice that the company considers sustainable. Radwanek-Bak and Kivinen (2016) explain the reasons of how legal and executive constraints can limit the activities or reduce the competitiveness of mining industries in Europe. Kemp et al (2016) analyze the differences between social risk and business risk in order to demonstrate how and where they interact, their impacts and how their comprehension plays a critical role in the industry's commitment to sustainable development. Ulyanova and Danchenkov (2016) present the marine space use conflicts, which include mining, and their likely environmental impact due to a lack of legislation and user-to-user level of solution.

Mining and partnerships for the goals (SDG17) Utzinger et al (2001) argue for a global partnership between development agencies, the private sector, banks, NGOs, foundations and researchers to develop and achieve goals to eradicate malaria, especially when they indicate the former program of the Roan Antelope mine of the copper belt in Zambia as an example. The partnerships can improve local capacities. Rendell (2016) discusses the ethical relations in a partnership between companies (financial support) and research institutions.

The paper of Jenkins and Yakovleva (2006) explores the trends in social and environmental disclosure by analysing the world's 10 largest mining companies. Despite of the disclosure of information not being a main target in any of the SDGs, it is related to them all. The research does not scrutinize all topics on environment and social issues applied to the mining sector, but points out how the companies' annual reports are made, their subject trends, most likely including health and safety, environmental and social issues, and most recently, economic impacts of 
mining operations. Perez and Sanchez (2009) also assessed sustainability reports. Those reports, as both groups of authors discuss, still need more maturation in form and regulation, so they can be compared and provide more reliable data.

Worrall et al (2009) develop a sustainable criteria and indicators framework for the legacy mine land by summarizing an extensive scheme that mentions environmental, social and economic indicators that lead to a better way of dealing with legacy mine land. They embrace almost all the SDGs topics, but lack on gender and education concerns.

\section{Conclusions}

The difficulties in criteria and metrics establishment, like presented by most of the authors, are reasons and drivers to the acceptance of the Sustainable Development Goals and of its targets by the mining industry. Therefore, how to incorporate sustainable development practices into the day to day of mining development and operations? Hilson and Murck (2000) argue that this issue requires some clear guidelines, practical rules and commitment from the companies and all the other involved. The SDGs' as a framework aims to offer more clear and common targets that can be supported by any mining company in any place of the world.

The results of this study showed that, in spite of a growing amount of publications in the past years that are related to mining and sustainability, the main focus of these publications are still on the environmental dimensions of the UN goals, with a few exceptions. The targets "poverty eradication (SDG1), zero hunger (SDG2), quality education (SDG4), gender equality (SDG5), innovation and infrastructure (SDG9), reduced inequalities (SDG10), climate action (SDG11) and life below water (SDG14)" presented no matches with the high impact or recent papers. It is known within the mining industry that leading companies are always striving to be innovative and develop new technologies that improve energy efficiency and reduce water consumption, for instance. It is an interesting finding that the key researchers and top papers have not been discussing these issues. The lack of discussion on the other SDGs leads to suggest that more practical and especially academic work in the mining sector is required to fill in the blank spaces regarding the other set of goals that composes the SDGs framework.

\section{Acknowledgement}

This research project is made possible through the financial support of the Government of Canada and the Government of Brazil with the financial support of the agency Coordenação de Aperfeiçoamento de Pessoal de Nível Superior - CAPES.

\section{References}

Alcott, B., 2005. Jevons' paradox. Ecological economics, 54(1): $9-21$.
Atlas, 2016. Mapping mining to the sustainable development goals: An atlas.

http://unsdsn.org/wpcontent/uploads/2016/11/Mapping_Mining_SDGs_An_ Atlas.pdf.

Costanza, R., L. Fioramonti and I. Kubiszewski, 2016. The UN sustainable development goals and the dynamics of well-being. Frontiers in Ecology and the Environment, 14(2): 59.

Custodio, E., 2002. Aquifer overexploitation: what does it mean? Hydrogeology Journal, 10(2): 254 - 277.

Diodato, V.P. and P. Gellatly, 2013. Dictionary of bibliometrics, Routledge.

Essah, M. and N. Andrews, 2016. Linking or de-linking sustainable mining practices and corporate social responsibility? Insights from Ghana. Resources Policy, 50: $75-85$.

Finfgeld-Connett, D., 2014. Use of content analysis to conduct knowledge-building and theory-generating qualitative systematic reviews. Qualitative Research, 14(3): $341-352$.

Calvo, G., G. Mudd, A. Valero and A. Valero, 2016. Decreasing ore grades in global metallic mining: A theoretical issue or a global reality? Resources, 5(4): 36.

Hilson, G. and B. Murck, 2000. Sustainable development in the mining industry: clarifying the corporate perspective. Resources Policy, 26(4): 227 - 238.

Jenkins, H. and N. Yakovleva, 2006. Corporate social responsibility in the mining industry: Exploring trends in social and environmental disclosure. Journal of Cleaner Production, 14(3): 271 - 284.

Kemp, D., 2010. Community relations in the global mining industry: Exploring the internal dimensions of externally orientated work. Corporate Social Responsibility and Environmental Management, 17(1): $1-14$.

Kemp, D., S. Worden and J.R. Owen, 2016. Differentiated social risk: Rebound dynamics and sustainability performance in mining. Resources Policy, 50: 19 - 26.

Krzemień, A., A.S. Sánchez, P.R. Fernández, K. Zimmermann and F.G. Coto, 2016. Towards sustainability in underground coal mine closure contexts: A methodology proposal for environmental risk management. Journal of Cleaner Production, 139: 1044 - 1056.

Malenović Nikolić, J., D. Vasović, I. Filipović, S. Mušicki and I. tović, 2016. Application of project management process on environmental management system improvement in mining-energy complexes. Energies, 9(12): 1071.

Mench, M., S. Bussiere, J. Boisson, E. Castaing, J. Vangronsveld, A. Ruttens, T. Koe, P. Bleeker, A. Assunção and A. Manceau, 2003. Progress in remediation and revegetation of the barren Jales gold mine spoil after in situ treatments. Plant and Soil, 249(1): 187 - 202.

Mudd, G.M., 2007. Global trends in gold mining: Towards quantifying environmental and resource sustainability. Resources Policy, 32(1): 42 - 56. 
Mudd, G.M., 2010. The environmental sustainability of mining in Australia: key mega-trends and looming constraints. Resources Policy, 35(2): 98 - 115.

Müller, D.B., T. Wang, B. Duval and T.E. Graedel, 2006. Exploring the engine of anthropogenic iron cycles. Proceedings of the National Academy of Sciences, 103(44): 16111 - 16116.

Owen, J.R. and D. Kemp, 2013. Social licence and mining: A critical perspective. Resources Policy, 38(1): 29 - 35.

Papong, S., N. Itsubo, Y. Ono and P. Malakul, 2016. Development of social intensity database using asian international input-output table for social life cycle assessment. Sustainability, 8(11): 1135.

Perez, F. and L.E. Sanchez, 2009. Assessing the evolution of sustainability reporting in the mining sector. Environmental Management, 43(6): 949 - 961.

Prno, J. and D.S. Slocombe, 2012. Exploring the origins of 'social license to operate in the mining sector: Perspectives from governance and sustainability theories. Resources Policy, 37(3): 346 - 357.

Radwanek-Bak, B. and M. Kivinen, 2016. Legal and formal factors related to the mineral raw material deposits accessibility in Europe. Gospodarka Surowcami Mineralnymi, 32(4): 59 - 72.

Rendell, J., 2016. Giving an account of oneself: architecturally. Journal of Visual Culture, 15(3): 334 348.

Sayer, J., T. Sunderland, J. Ghazoul, J.L. Pfund, D. Sheil, E. Meijaard, M. Venter, A.K. Boedhihartono, M. Day, C. Garcia, C. van Oosten and L.E. Buck, 2013. Ten principles for a landscape approach to reconciling agriculture, conservation, and other competing land uses. Proceedings of the National Academy of Sciences, 110(21): 8349 - 8356.

Salinas, C.X., J. Gironás and M. Pinto, 2016. Water security as a challenge for the sustainability of La SerenaCoquimbo conurbation in northern Chile: global perspectives and adaptation. Mitigation and Adaptation Strategies for Global Change, 21(8): 1235 - 1246.

Starke, L., 2016. Breaking new ground: mining, minerals and sustainable development. Routledge.

Ulyanova, M., and A. Danchenkov, 2016. Maritime potential of the Russian sector of the south-eastern Baltic Sea and its spatial usage. Baltica, 29(2): 133 134.

Utzinger, J., Y. Tozan and B.H. Singer, 2001. Efficacy and cost-effectiveness of environmental management for malaria control. Tropical Medicine \& International Health, 6(9): 677 - 687.

Walker, W., S. Grugeon, O. Mentre, S. Laruelle, J.M. Tarascon, and F. Wudl, 2010. Ethoxycarbonyl-based organic electrode for Li-batteries. Journal of the American Chemical Society, 132(18): 6517 - 6523.

West, N.E., 1993. Biodiversity of rangelands. Journal of Range Management, 46(1): 2 - 13.

Whitmore, A., 2006. The emperor's new clothes: Sustainable mining? Journal of Cleaner Production, 14(3): 309 - 314.

Worrall, R., D. Neil, D. Brereton and D. Mulligan, 2009. Towards a sustainability criteria and indicators framework for legacy mine land. Journal of Cleaner Production, 17(16): 1426 - 1434. 